\title{
Seleção de clones de batata para microclimas de altitude no Planalto Central
}

\author{
Nei Peixoto'; Fernando Antonio R. Filgueira²; Paulo Eduardo de Melo³; José Amauri Buso³ Jair D. \\ Monteiro $^{4}$; Leila T. Braz ${ }^{5}$ Luis F.V. Purquerio ${ }^{5}$; Roberto I. Hamasaki ${ }^{5}$

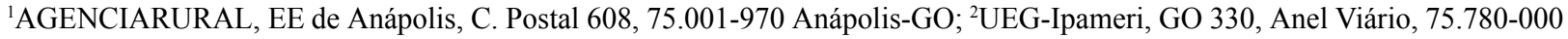 \\ Ipameri-GO; ${ }^{3}$ Embrapa Hortaliças, C. Postal 218, 70.359-970 Brasília-DF; ${ }^{4}$ Escola Agrotécnica Federal 75.790-000 Urutaí-GO; ${ }^{5}$ UNESP, \\ 14.870-000 Jaboticabal-SP. E-mail: nei.p@terra.com.br
}

\section{RESUMO}

Iniciou-se em 1986, em Anápolis, um programa de desenvolvimento de cultivares de batata adaptadas ao clima de altitude do Brasil Central, partindo-se de 15.000 genótipos, resultantes de 200 famílias obtidas pela Embrapa Hortaliças em 1985 e 1986. No primeiro ciclo, em 1986, foram selecionados 5.000 genótipos, considerando-se aspectos fenológicos, incidência de doenças, qualidade dos tubérculos e potencial de produção. Esses mesmos critérios foram adotados nas gerações posteriores, selecionando-se, anualmente, 15$20 \%$ de genótipos superiores. Em 1990 avaliaram-se 52 destes clones, tendo como testemunhas as cultivares Achat e Bintje; Destes foram selecionados 28 clones promissores que foram submetidos à cultura de ápices caulinares e à indexação para os vírus PLRV, PVY e PVX na Embrapa Hortaliças. No período de 1995 a 1997 foram avaliados em Goiás, nos municípios de Anápolis, Morrinhos, Pirenópolis e Urutaí, e em Jaboticabal. Os dados foram submetidos à análise de variância, e aqueles referentes a 14 genótipos em 7 ambientes, à regressão pelo método de Eberhart \& Russell. Os clones BAT 2, BAT 3, BAT 4, BAT 19, BAT 27 e BAT 28 destacaram-se entre os mais produtivos, considerando-se, também, as características de tubérculos para o consumo. Os genótipos responderam proporcionalmente à melhoria do ambiente. O clone BAT 19 foi o mais estável.

Palavras-chave: Solanum tuberosum, melhoramento genético, produtividade, adaptabilidade, estabilidade.

\begin{abstract}
Selection of potato cultivars for high altitude microclimates in Central Brazil
\end{abstract}

A potato selection program was done in Anapolis, State of Goias, Brazil, beginning in 1986 with 15,000 genotypes, resulting from 200 crosses obtained by Embrapa Hortaliças in 1985 and 1986. In the first selection cycle, in 1986, 5,000 genotypes were selected, considering plant growth and development, disease incidence, tuber quality and yield potential. These criteria were also adopted in further generations, when 15 to $20 \%$ of the best genotypes were yearly selected. In 199052 of the selected genotypes were evaluated in comparison with the cultivars Achat and Bintje. The best 28 clones were then named BAT, cleaned by meristem tip culture and evaluated from 1995 to 1997 at Anápolis, Morrinhos, Pirenópolis, Urutaí and Jaboticabal. All data were submitted to the analysis of variance. In addition, data from fourteen genotypes in seven environments were analyzed by the linear regression technique of Ebehart \& Russell. Clones BAT 2, BAT 3, BAT 4, BAT 19, BAT 27 and BAT 28 ranked best among the highest yielding ones, in addition to good tuber quality. Genotypes had similar behavior regarding adaptability, responding in a proportional way to environment improvement. BAT 19 was the most stable clone.

Keywords: Solanum tuberosum, breeding, yield, adaptability, stability.

\section{(Recebido para publicação em 25 de julho de 2000 e aceito em 15 de fevereiro de 2002)}

\begin{abstract}
$\mathrm{A}$ batata é a hortaliça que ocupa o primeiro lugar em volume de comercialização em Goiás, mas é pequena a produção estadual, apesar das excelentes condições edafoclimáticas das áreas de maior altitude do estado, como tem sido demonstrado pela pesquisa (Filgueira et al., 1978; Filgueira \& Câmara, 1982; Peixoto \& Filgueira, 1995). Entre os bataticultores obtêm-se rendimentos superiores a $30 \mathrm{t} / \mathrm{ha}$, utilizando-se cultivares européias, principalmente Achat e Bintje. A principal limitação à expansão do cultivo, mormente entre pequenos olericultores, é a indisponibilidade de batata-semente no mercado local bem como as exigências tecnológicas para o cultivo
\end{abstract}

das cultivares disponíveis. Assim, a seleção de cultivares melhor adaptadas poderá resultar no incremento da produção regional, além de oferecer alternativas de renda aos produtores.

Um programa de melhoramento genético, objetivando desenvolver cultivares adaptadas a condições edafo-climáticas específicas, com resistência ou tolerância às principais doenças que ocorrem na região é um passo importante para o sucesso na cultura, por resultar na redução do custo de produção e dos impactos negativos dos defensivos sobre o ambiente e a saúde humana.

No Planalto Central as doenças mais limitantes têm sido as viroses e a pinta- preta. Os vírus, transmitidos por vetores, acumulam-se nos tubérculos ao longo dos plantios sucessivos, afetando seriamente o desenvolvimento e produção (Câmara et al., 1986; Filgueira \& Câmara, 1986). As viroses podem ser eficientemente controladas, utilizando-se cultivares resistentes (Davies et al., 1975) ou batata-semente livre desses patógenos. A pinta preta (A. solani) por outro lado, pode ser controlada, utilizando-se fungicidas específicos o que, dependendo da cultivar, requer dezenas de pulverizações. O uso de cultivares resistentes é, sem dúvida, a opção mais racional ao seu controle (Reifschneider et al., 1986). 
Tabela 1. Produção de tubérculos comerciáveis, em t/ha, de genótipos de batata em diversas regiões. Anápolis, EMATER-GOIÁS, $1995-1997$.

\begin{tabular}{|c|c|c|c|c|c|c|c|c|}
\hline $\begin{array}{l}\text { Clone/ } \\
\text { Cultivar }\end{array}$ & $\begin{array}{l}\text { Anápolis } \\
31 / 08 / 95 \\
\end{array}$ & $\begin{array}{l}\text { Anápolis } \\
29 / 05 / 96\end{array}$ & $\begin{array}{c}\text { Morrinhos } \\
16 / 05 / 96 \\
\end{array}$ & $\begin{array}{c}\text { Pirenópolis } \\
04 / 06 / 96 \\
\end{array}$ & Urutaí 20/05/96 & $\begin{array}{l}\text { Anápolis-E- } \\
\text { EA 01/04/97 }\end{array}$ & $\begin{array}{c}\text { Anápolis-EA } \\
30 / 04 / 97 \\
\end{array}$ & $\begin{array}{c}\text { Jaboticabal } \\
05 / 04 / 97 \\
\end{array}$ \\
\hline BAT 1 & $33,31 a b$ & $47,48 a b$ & $25,42 a b c d e$ & $31,35 a b c d$ & $45,27 a b c$ & $20,38 a b$ & $11,42 b c$ & $17,74 \mathrm{cde}$ \\
\hline BAT 2 & $40,86 a$ & $48,11 a b$ & $29,29 a b c d$ & $30,60 a b c d$ & 32,32cdefghi & $21,46 a b$ & $13,35 a b c$ & $31,01 \mathrm{abc}$ \\
\hline BAT 3 & $30,47 a b c d$ & $42,63 a b c d$ & $32,56 a b$ & $34,35 a b c$ & 43,62abcde & $18,38 a b$ & $12,57 \mathrm{bc}$ & $38,15 a b$ \\
\hline BAT 4 & $33,52 \mathrm{ab}$ & $47,41 \mathrm{ab}$ & $26,25 a b c d e$ & $42,14 a$ & $51,29 a$ & $20,93 a b$ & $16,63 a b$ & $27,74 \mathrm{bcd}$ \\
\hline BAT 5 & 20,96 cdefghij & $38,95 \mathrm{bcde}$ & 25,30 abcde & - & 30,92defghi & - & - & $16,05 \mathrm{de}$ \\
\hline BAT 6 & 19,50defghij & $40,63 \mathrm{bcde}$ & $31,85 a b c$ & $28,45 a b c d$ & $38,21 \mathrm{abcdefg}$ & $10,07 \mathrm{cde}$ & - & $10,77 \mathrm{e}$ \\
\hline BAT 7 & $13,33 i j$ & $35,11 \mathrm{cde}$ & $18,93 \mathrm{cdef}$ & - & - & - & $09,19 b c$ & - \\
\hline BAT 8 & $28,48 \mathrm{bcdef}$ & $46,69 a b$ & $21,46 \mathrm{bcdef}$ & $26,67 \mathrm{bcde}$ & 42,56abcde & $17,15 a b c$ & $14,29 a b c$ & 20,30 cde \\
\hline BAT 9 & $33,28 a b$ & $45,09 a b$ & $29,52 \mathrm{abcd}$ & $30,48 a b c d$ & $28,15 f g h i$ & $17,03 a b c$ & $11,49 b c$ & 19,43 cde \\
\hline BAT 10 & 14,65hij & $43,72 \mathrm{abcd}$ & 22,92abcde & - & $36,72 \mathrm{bcdefgh}$ & $15,83 a b c$ & - & - \\
\hline BAT 11 & $27,87 \mathrm{bcdefg}$ & $38,94 \mathrm{bcde}$ & 23,69abcde & $28,87 a b c d$ & 30,25defghi & - & $05,43 c$ & - \\
\hline BAT 12 & $27,54 \mathrm{bcdefg}$ & $44,87 a b$ & 25,42abcde & $28,45 \mathrm{abcd}$ & $22,56 \mathrm{ij}$ & $10,01 \mathrm{cde}$ & $09,74 b c$ & $17,02 \mathrm{cde}$ \\
\hline BAT 13 & $29,84 a b c d e$ & $44,07 a b c d$ & $30,77 \mathrm{abcd}$ & $25,77 \mathrm{bcde}$ & $27,55 \mathrm{ghi}$ & $15,22 \mathrm{abcd}$ & $10,15 b c$ & $24,76 \mathrm{bcde}$ \\
\hline BAT 14 & $21,89 \mathrm{bcdefghij}$ & $30,90 \mathrm{cdef}$ & $19,41 \mathrm{bcdef}$ & $27,80 \mathrm{bcd}$ & $23,14 \mathrm{hij}$ & - & - & - \\
\hline BAT 15 & 24,96bcdefghij & $39,05 \mathrm{bcde}$ & 23,27 abcde & 23,10 cde & $26,85 \mathrm{ghi}$ & - & $06,80 c$ & 19,79 cde \\
\hline BAT 16 & 29,82abcde & $30,59 \mathrm{def}$ & 20,06 bcdef & $29,88 \mathrm{abcd}$ & $42,86 a b c d$ & - & - & - \\
\hline BAT 17 & 19,89defghi & $37,82 \mathrm{bcde}$ & 23,45abcde & $28,63 a b c d$ & 42,47abcde & $10,27 \mathrm{cde}$ & $07,99 b c$ & 22,79 cde \\
\hline BAT 18 & 23,13bcdefghij & $34,63 \mathrm{bcde}$ & $17,92 \mathrm{def}$ & $23,45 \mathrm{cde}$ & $10,63 j$ & - & - & - \\
\hline BAT 19 & $31,79 \mathrm{abcd}$ & $47,13 a b$ & 24,52abcde & $37,98 a b$ & $41,60 a b c d e f$ & $16,61 \mathrm{abc}$ & $13,43 a b c$ & $26,55 \mathrm{bcd}$ \\
\hline BAT 20 & 19,93defghij & $38,73 \mathrm{bcde}$ & $17,56 \mathrm{def}$ & 25,60 bcde & $24,23 \mathrm{hij}$ & - & - & - \\
\hline BAT 21 & $12,42 \mathrm{j}$ & $26,88 \mathrm{ef}$ & 20,42 bcdef & - & - & - & - & - \\
\hline BAT 22 & $28,06 \mathrm{bcdefg}$ & $38,80 \mathrm{bcde}$ & $18,63 \mathrm{cdef}$ & $26,61 \mathrm{bcde}$ & 32,53cdefghi & - & - & - \\
\hline BAT 23 & 19,37efghij & $37,93 \mathrm{bcde}$ & 18,16 def & $24,05 \mathrm{bcde}$ & 29,08 efghi & - & - & - \\
\hline BAT 24 & $33,50 a b$ & $40,90 \mathrm{bcd}$ & $19,82 \mathrm{bcdef}$ & $25,30 \mathrm{bcde}$ & 30,83defghi & $13,48 \mathrm{bcd}$ & $11,51 b c$ & $10,30 \mathrm{e}$ \\
\hline BAT 25 & 25,45 bcdefghi & $43,99 a b c d$ & $19,58 \mathrm{bcdef}$ & $18,69 \mathrm{de}$ & 30,45defghi & - & - & - \\
\hline BAT 26 & $12,17 \mathrm{j}$ & $48,31 \mathrm{ab}$ & $09,46 f$ & - & - & - & - & - \\
\hline BAT 27 & $32,25 a b c$ & $44,70 a b c$ & 29,52, abcd & - & $48,45 a b$ & $19,50 a b$ & $10,51 b c$ & $23,39 \mathrm{cde}$ \\
\hline BAT 28 & $16,80 f g h i j$ & $55,05 a$ & $34,76 a$ & - & $41,52 a b c d e f$ & $22,39 a$ & $22,35 a$ & $42,44 a$ \\
\hline ACHAT & 15,91ghij & $12,68 c$ & $14,23 \mathrm{ef}$ & $12,68 c$ & $26,46 \mathrm{ghi}$ & $03,45 \mathrm{e}$ & $06,64 c$ & $11,43 \mathrm{e}$ \\
\hline BINTJE & 25,64 cdefgh & - & - & - & $26,31 \mathrm{ghi}$ & $13,81 \mathrm{bcd}$ & $09,24 b c$ & $23,39 \mathrm{cde}$ \\
\hline MONALISA & 20,38 cdefghi & - & - & - & $11,70 \mathrm{j}$ & $07,24 \mathrm{de}$ & - & - \\
\hline CV\% & 18,07 & 12,40 & 18,32 & 16,66 & 13,12 & 21,58 & 27,44 & 21,08 \\
\hline
\end{tabular}

Médias seguidas da mesma letra, na coluna, não diferem entre si pelo teste de Tukey ao nível de 5\%

Objetivou-se identificar clones produtivos, tolerantes às viroses PVY e PLRV e à pinta-preta com tubérculos de boa qualidade comercial para consumo in natura ou processamento, adaptados às condições edafoclimáticas regionais, com vistas à posterior liberação dos melhores clones como novas cultivares.

\section{MATERIAL E MÉTODOS}

As seleções iniciaram-se em 1986, em Anápolis, em condições de campo, partindo-se, inicialmente, de 15.000 clones resultantes de 200 cruzamentos realizados pela Embrapa Hortaliças em 1985 e 1986. Os plantios foram efetuadas em solos com cobertura original de cerrado, em altitudes variando de 980 a 1000 m, na EE de Anápolis.

Foram feitas, anualmente, seleções entre clones, considerando-se o desenvolvimento das plantas, incidência de doenças (Alternaria solani, PVY e PLRV), aspectos externos e internos de tubérculos e o potencial aparente de produção. Considerou-se o conjunto de todas as plantas da parcela, para tomada de decisão do que seria selecionado para o próximo ciclo. Esses mesmos critérios foram adotados nas gerações posteriores, selecionando-se, anualmente, 15 a $20 \%$ dos genótipos superiores. A cada geração a batata-semente resultante das seleções era encaminhada à Embrapa Hortaliças, onde era mantida, em câmara fria, até a próxima época de plantio, no outono.

No primeiro ciclo de seleção, em 1986, foram selecionados cerca de 5.000 genótipos seguindo-se seleções em 1988 e 1989, quando foi efetuada a seleção que resultou em 52 clones promissores. Estes foram avaliados em 1990, utilizando-se como testemunhas as cultivares Achat e Bintje. Os 34 clones que se destacaram, todos superando estatisticamente as testemunhas, foram encaminhados à Embrapa Hortaliças para serem submetidos à cultura de ápices caulinares e indexação para os virus 
Tabela 2. Análise de adaptabilidade e estabilidade de doze genótipos avaliados em oito ambientes, de acordo com o método de Eberhart \& Russell (1966), segundo o modelo $\mathrm{Y}_{\mathrm{ij}}=\alpha_{\mathrm{i}}+\beta_{\mathrm{i}} \mathrm{I}_{\mathrm{j}}+\delta_{\mathrm{ij}}$

\begin{tabular}{|c|c|c|c|c|c|}
\hline \multirow{2}{*}{$\begin{array}{c}\text { Genótipo } \\
\text { (Clone/cultivar) }\end{array}$} & \multirow{2}{*}{$\begin{array}{c}\text { Produção média } \\
(\mathrm{t} / \mathrm{ha})\left({ }_{i}\right)\end{array}$} & \multicolumn{2}{|c|}{ Coeficiente de regressão linear } & \multirow{2}{*}{$\begin{array}{l}\text { Desvio de } \\
\text { regressão }\end{array}$} & \multirow{2}{*}{$\begin{array}{l}\text { Coeficiente de } \\
\text { Determinação } R^{2}\end{array}$} \\
\hline & & $\left(i_{i}\right)$ & $t\left({ }_{i}\right)$ & & \\
\hline BAT 01 & $29,60 a b$ & 1,1528 & $0,93 \mathrm{~ns}$ & $15,2293^{* *}$ & $0,9080^{* *}$ \\
\hline BAT 02 & $30,85 a b$ & 0,8998 & $-0,50 \mathrm{~ns}$ & $25,2773^{* *}$ & $0,8024^{* *}$ \\
\hline BAT 03 & $30,79 a b$ & 0,9107 & $-0,41 \mathrm{~ns}$ & $31,5003^{* *}$ & $0,7759^{* *}$ \\
\hline BAT 04 & $31,55 a b$ & 1,0684 & $0,39 \mathrm{~ns}$ & $17,9918^{* *}$ & $0,8822^{* *}$ \\
\hline BAT 08 & $27,17 a b$ & 1,0595 & $0,44 \mathrm{~ns}$ & $8,4193^{*}$ & $0,9251 * *$ \\
\hline BAT 09 & $26,00 a b$ & 0,8793 & $-0,74 \mathrm{~ns}$ & $15,0489^{*}$ & $0,8527^{* *}$ \\
\hline BAT 12 & $21,97 b c$ & 1,0444 & $0,22 \mathrm{~ns}$ & $26,1976^{* *}$ & $0,8416^{* *}$ \\
\hline BAT 13 & $25,96 a b c$ & 0,9181 & $-0,49 n s$ & $15,9577^{* *}$ & $0,8581^{* *}$ \\
\hline BAT 17 & $22,98 b c$ & 1,0810 & $0,47 n s$ & $17,2172^{* *}$ & $0,8879 * *$ \\
\hline BAT 19 & $28,89 a b$ & 1,0520 & $0,66 \mathrm{~ns}$ & $-0,9669 n s$ & $0,9731^{* *}$ \\
\hline BAT 24 & $22,45 b c$ & 0,8850 & $-0,53 n s$ & $30,9027^{* *}$ & $0,7688^{* *}$ \\
\hline ACHAT & $16,75 c$ & 1,0691 & $0,49 \mathrm{~ns}$ & $9,7063^{*}$ & 0,9201 * * \\
\hline BAT-27 & $29,40 a b$ & 1,1064 & $0,64 \mathrm{~ns}$ & $15,9047^{* *}$ & 0,8980 ** \\
\hline BAT-28 & $33,50 a$ & 0,8737 & $-0,35 \mathrm{~ns}$ & $93,1016^{* *}$ & $0,5457 \mathrm{~ns}$ \\
\hline
\end{tabular}

ns $=$ não significativo $*$ significativo ao nível de $5 \%$ e **= significativo ao nível de $1 \%$ de probabilidade estatística.

Médias seguidas da mesma letra, na coluna, não diferem entre si pelo teste de Tukey ao nível de 5\%

PLRV,PVX e PVY, juntamente com Achat, Bintje e Monalisa. Destes clones, os 28 mais promissores foram denominados, em conjunto, como série BAT. As respectivas genealogias constam no artigo de Filgueira (1995).

Os clones da série BAT foram posteriormente avaliados, em uma série de ensaios de produção, em 1995 (Anápolis), 1996 (Anápolis, Morrinhos, Pirenópolis e Urutaí), no Estado de Goiás. Em 1997 foram conduzidos três ensaios: na Estação Experimental de Anápolis (EEA), na Escola Agrícola de Anápolis (EA) e na UNESP-Jaboticabal. $\mathrm{O}$ delineamento experimental utilizado foi de blocos casualizados, com três ou quatro repetições, e parcelas úteis de 20 plantas dispostas no espaçamento de $0,80 \times 0,35 \mathrm{~m}$. Utilizou-se como adubação, $3 \mathrm{t} / \mathrm{ha}$ da fórmula 4-16-8 no plantio e $300 \mathrm{~kg} / \mathrm{ha}$ de sulfato de amônio em cobertura, cerca de 30 dias após o plantio, seguida da amontoa.

A batata-semente utilizada em 1995 foi produzida em telado na Embrapa Hortaliças, a partir de batata-semente pré-básica. Para os demais experimentos foram utilizadas aquelas produzidas em Anápolis, no experimento do respectivo ano anterior.
Foram realizados os tratos culturais e fitossanitários normais para a cultura, incluindo-se irrigação por aspersão, em todos os experimentos.

Obtiveram-se os dados de produção total de tubérculos que foram submetidos à análise de variância, para cada experimento, e as médias comparadas pelo teste de Tukey a 5\% de probabilidade estatística, utilizando-se o programa ESTAT. Os dados de produção total dos quatorze genótipos comuns a sete experimentos foram também submetidos à análise de adaptabilidade e estabilidade, segundo Eberhart \& Russell (1966), utilizando-se o programa IGA, desenvolvido por Banzatto (1994).

\section{RESULTADOS E DISCUSSÃO}

Observaram-se diferenças significativas entre os genótipos em todos os experimentos. Destacaram-se entre os mais produtivos os clones BAT 1, BAT 2, BAT 3, BAT 4, BAT 19, BAT 27 e BAT 28, considerando-se, também, as características de tubérculos para o consumo. Todos estes clones superaram as cultivares Bintje, Monalisa, nos experimentos em que foram incluídas e a cultivar Achat (Tabela 1).
Estes clones apresentam como características comuns gemas superficiais e película lisa e amarelada. Com exceção de BAT-27, com polpa branca, todos os demais apresentam polpa amarela. Os tubérculos dos clones BAT-1, BAT-2 e BAT-19 são alongados; os de BAT-3 e BAT-27 arredondados; os de BAT-4 arredondados e alongados; os de BAT-28 fusiformes. Apresentam película lisa, exceto BAT-27 e BAT-28 que, em certas situações apresentam ligeira aspereza, em alguns tubérculos.

O clone BAT-28 apresentou, na análise conjunta, a maior média de rendimento de tubérculos, apesar do fraco desempenho no experimento de Anápolis, 1995, quando foram utilizados tubérculos produzidos em telado como material de plantio. Esse fato talvez explique o correspondente elevado valor do desvio de regressão, o que sugere imprevisibilidade de comportamento, e do baixo coeficiente de determinação com plantios oriundos de tubérculos-semente menores (tabela 2). Entretanto, BAT 28 manteve-se entre os genótipos mais produtivos, nos demais experimentos (Tabela 1).

$\mathrm{Na}$ avaliação da adaptabilidade, 13 clones e a cultivar Achat, comuns a 7 
ensaios, comportaram-se de maneira semelhante, respondendo proporcionalmente à melhoria do ambiente para a característica produtividade. O clone BAT 19 foi o genótipo mais estável, apresentando, também, rendimentos satisfatórios (Tabela 2).

Estes resultados demonstram a possibilidade de se obter, por seleção regional, clones aliando produtividade e características de tubérculos similares ou melhores do que das cultivares comerciais regionalmente utilizadas. Embora desenvolvidos para o Planalto Central, os clones BAT 28, BAT 2 e BAT 3 apresentaram comportamento satisfatório, também em Jaboticabal, o que poderá possibilitar a sua indicação para áreas fora daquela para a qual foram desenvolvidos. Os clones que se destacaram serão avaliados em parcelas maiores, junto a produtores, visando a identificação dos melhores para futura liberação como novas cultivares.

\section{AGRADECIMENTOS}

Aos técnicos agrícolas Francisco da Mota Moreira, Josimar Alberto Pereira, Laureano Magno Vargas e Israel dos Santos de Souza e aos alunos da Escola Agrotécnica Federal de Urutaí, pela condução dos trabalhos de campo e ao agricultor Waldivino Canedo por ceder a área para condução do experimento de Pirenópolis.

\section{LITERATURA CITADA}

BANZATTO, D.A. Comparação de métodos de avaliação da adaptabilidade e estabilidade de cultivares de batata. Jaboticabal: FCAV, 1994. 170 p. (Tese livre docência).

CÂMARA， F.L.A.; CUPERTINO， F.P.; FILGUEIRA, F.A.R. Redução da produtividade de cultivares de batata causada por virus. Horticultura Brasileira, Brasília, v. 4, n. 2, p. 810, 1986.

DAVIES, H.T.; McEWEN, H.L.; NIXON, N.C. Field testing potatoes for resistance to leafroll and virus Y. American Potato Journal, v. 52, p. 151$155,1975$.
EBERHART, S.A; RUSSELL, W.A. Stability parameters for comparing varieties. Crop Science, v. 6, n. 1, p. 36-40, 1966.

FILGUEIRA, F.A.R. Melhoramento genético de batata para regiões de cerrado - um depoimento pessoal. Horticultura Brasileira, Brasília, v. 13, n. 2, p. 129-132, 1995

FILGUEIRA, F.A.R; BANZATTO, D.A.; CHURATA-MASCA, M.G.C.; CASTELLANE, P.D. Interação genótipo $\mathrm{x}$ ambiente em batata. Horticultura Brasileira, Brasília, v. 13, n. 2, p. 134-141, 1995.

FILGUEIRA, F.A.R.; CÂMARA, F.L.A. Comportamento de trinta e sete cultivares de batata, nos períodos seco e chuvoso em Anápolis. Goiânia: EMGOPA, 1982. 31 p. (Boletim Técnico, 10).

FILGUEIRA, F.A.R.; CÂMARA, F.L.A. Comportamento de cultivares européias de batata em gerações sucessivas. Horticultura Brasileira, Brasília, v. 4, n. 1, p. 29-31, 1986.

FILGUEIRA, F.A.R; SONNENBERG, P.E.; OGATA, T.; PEIXOTO, N. Comportamento de cultivares europeus de batata, nos períodos seco e chuvoso em Anápolis. Goiânia: EMGOPA, 1978, 11 p. (EMGOPA. Comunicado Técnico 11). PEIXOTO, N.; FILGUEIRA, F.A.R. Avaliação de cultivares de batata em Anápolis (1988/91). Goiânia: EMGOPA, 1995. 12 p. (EMGOPA. Boletim de Pesquisa, 29).

REIFSCHNEIDER, F.J.B.; CORDEIRO, C.M.T.; FILGUEIRA, F.A.R. Resistência de batata a $\mathrm{Al}$ ternaria solani. Horticultura Brasileira, Brasília, v. 4, n. 2, p. 22-25, 1986. 